\title{
EFFECTS OF DESLORELIN ACETATE ON PLASMA TESTOSTERONE CONCENTRATIONS IN CAPTIVE YELLOW-BELLIED SLIDERS (TRACHEMYS SCRIPTA SP.)
}

\author{
Romain Potier ${ }^{1 *}$, Emma MongE$^{2}$, Tatiana LouCACHEVSKY ${ }^{1}$, Robert Hermes $^{3}$, \\ Frank GÖRITZ ${ }^{3}$, Daphné RoCHEL ${ }^{4}$ and Emmanuel RISI ${ }^{1}$ \\ ${ }^{1}$ FauneVet, CHV Atlantia, 44200 Nantes, France; ${ }^{2}$ Exotic and Wildlife Clinic, \\ Toulouse National Veterinary School, Toulouse, France; ${ }^{3}$ Leibniz Institute for Zoo and \\ Wildlife Research, Berlin, Germany; ${ }^{4}$ LDHVet, Nantes Atlantic College of \\ Veterinary Medicine, Nantes, France
}

(Received 29 March 2017; accepted 4 April 2017)

In Europe, the yellow-bellied slider (Trachemys scripta sp.) is a non-native species in competition with native freshwater turtles. Research on contraception could be useful to control the captive population. Identifying a method of contraception in chelonians would potentially help to control aggression in other chelonian species. The objective of the current study was to evaluate the effects of a single 4.7-mg deslorelin acetate implant on plasma testosterone concentrations in yellow-bellied sliders (Trachemys scripta $\mathrm{sp}$.). Eleven adult male yellow-bellied sliders were used for the study. Males from the treatment group $(n=6)$ received a 4.7-mg deslorelin acetate implant, whereas males from the control group $(n=5)$ did not receive any treatment. All individuals were housed under the same environmental conditions. Testosterone plasma concentrations of the control group and the treatment group were measured at six time points (T0-T6) between April and September. No difference between the control group and the deslorelin treatment group was observed at T0, T2, T3, T4, T5 or T6. However, mean plasma testosterone concentration was significantly higher in the treatment group than in the control group at $\mathrm{T} 1$. This suggests that treatment with a 4.7-mg deslorelin acetate implant has a transient stimulatory effect on the anterior pituitary in yellowbellied sliders without a negative feedback on testosterone production. Further studies with a higher dosage of deslorelin acetate are needed to draw conclusions on its contraceptive effect.

Key words: Trachemys scripta, yellow-bellied slider, testosterone, GnRH agonist, contraception

Freshwater sliders (Trachemys scripta $\mathrm{sp.)}$ are non-native turtles imported massively into Europe in the early 1970s for pet trade. They are now considered an invasive species threatening native freshwater turtles (Polo-Cavia et al.,

*Corresponding author; E-mail: r.potier@faunevet.fr; Phone: 0033 (0)6 72798465 
2012). As such, contraception could be useful to control population growth in captive settings and limit spillover into the wild. Research on contraception in chelonians might also help to identify methods to control aggression in other chelonian species in captivity such as the African spurred tortoise (Geochelone sulcata). The use of deslorelin implants for such purposes has already been described in lizards (Rowland, 2011). Seasonal cycles in testicular activity and plasma steroid levels have been studied in a variety of turtles. In single-clutched freshwater turtles such as Chrysemis picta and Graptemys flavimaculata, sex steroid hormones show two peaks; one in the spring at the end of wintering, and another in the autumn (Licht et al., 1985; Shelby et al., 2000). As in most vertebrate species, the hypothalamo-pituitary-gonadal axis seems to control this reproductive cycle. Pulsatile GnRH secretions from the hypothalamus stimulate the release of luteinising hormone (LH) and follicle stimulating hormone (FSH) from the anterior pituitary. Synthetic GnRH agonists such as deslorelin acetate have been found to reduce sex hormone production in mammalian and avian species when applied long term (Petritz et al., 2015). After initial stimulatory effects, synthetic GnRH agonists down-regulate LH and FSH secretions by saturating the pituitary GnRH receptors. Deslorelin acetate is formulated in a controlled-release implant designed for subcutaneous administration in dogs for reversible suppression of testosterone production. It is commercially available as 4.7- and 9.4-mg implants (Suprelorin, Virbac, Carros, France) and labelled for male dogs and ferrets. The purpose of this study was to evaluate the effect of a 4.7-mg deslorelin acetate implant on plasma testosterone concentrations in intact male yellow-bellied freshwater sliders at the onset of the breeding season.

\section{Materials and methods}

Two veterinary schools and one research institute were involved in the study design which did not raise any ethical concerns. No turtles were killed at the end of the study. Eleven healthy, adult male yellow-bellied sliders (Trachemys scripta sp.) from various zoological collections were used in the study. Males were first selected using morphological criteria. In yellow-bellied sliders, males are smaller than females and they have longer front nails. Their correct sex was confirmed by endoscopic examination and visualisation of the testis. Endoscopic examination and biochemistry test were used to confirm the correct sex and the health status of all subjects. All turtles were weighed and for the purpose of animal identification a microchip was inserted subcutaneously in the left prefemoral fossa (Virbac Biotec Slim Puce Faune Sauvage, Virbac, Carros, France). Once selected, turtles were transferred into one shared outdoor exhibit with a $7.5-\mathrm{m}^{3}$ freshwater pond for the duration of the study. Water temperature was variable and depended on meteorological condition. Males were randomly di- 
POTIER et al.

vided into two groups: control group (group $1, \mathrm{n}=5$ ) and deslorelin treatment group (group 2, $\mathrm{n}=6$ ). In the treatment group, one deslorelin acetate implant (Suprelorin $4.7 \mathrm{mg}$, Virbac, Carros, France) was inserted subcutaneously in the right prefemoral fossa.

All blood samples were collected from the subcarapacial sinus between 1 April and 8 September (T6) in 2016. After implant insertion (T0), plasma testosterone concentrations were measured at six time points: T1 (mean \pm SD days after T0; $12 \pm 5$ days), T2 (26 \pm 4 days), T3 (55 \pm 5 days), T4 (87 \pm 6 days), T5 (118 \pm 14 days) and T6 (149 \pm 16 days). Capture and blood sampling were performed within a one-hour time frame to avoid stress-induced suppression of gonadal hormones (Licht et al., 1985). All blood samples were immediately transferred to a heparinised vial and centrifuged. Plasma was pipetted into cryogenic vials and stored at $-20{ }^{\circ} \mathrm{C}$ until assayed.

Testosterone was extracted and isolated from plasma with cyclohexane and ethyl acetate (1:1). The residue was dissolved in a Tris-Bovine Serum Albumin-Triton buffer prior to the assay. Total testosterone was measured with a commercial immunoradiometric kit (Testo-CT2, Cisbio Bioassays, Codolet, France) based on a competitive method between endogenous testosterone and

${ }^{125}$ I-labelled testosterone for rabbit testosterone antibodies. All the assays were performed in accordance with the manufacturer's instructions at LDHVet in Nantes Atlantic College of Veterinary Medicine. The manufacturer's validation data (linearity between 0.1 and $50.0 \mathrm{nmol} / \mathrm{L})$ and analytical sensitivity $(0.1 \mathrm{nmol} / \mathrm{L})$ for this kit were verified in situ at three levels $(5,23$ and $40 \mathrm{nmol} / \mathrm{L})$ with $20 \mathrm{rep}-$ licates per level. Maximal inter-assay coefficients of variation (CVs) were then $10 \%$ for the low level, $8 \%$ for the medium level and $10 \%$ for the high level.

A Mann-Whitney U-test (Wilcoxon rank sum test) was used to compare groups within sampling time. Statistical tools based on Microsoft Excel ${ }^{\circledR}$ (available on http://www.anastats.fr) were used to analyse the data. $\mathrm{P}<0.05$ was considered statistically significant.

\section{Results}

Body weight (mean $\pm \mathrm{SD}$ ) was $0.71 \pm 0.18 \mathrm{~kg}$. No difference between the control and the deslorelin-treated groups was observed at T0, T2, T3, T4, T5 or T6. Plasma testosterone mean concentration was significantly higher in the deslorelin-treated group than in the control group at T1 (Fig. 1, P = 0.041, MannWhitney U-test).

\section{Discussion}

Testosterone concentrations recorded in the treatment and the control group were of the same order of magnitude as previously reported in other freshwater turtle species for the same time of year (Callard et al., 1976; Licht et 
al., 1985; Shelby et al., 2000). A subcutaneous deslorelin acetate controlledrelease implant at the dose of $4.7 \mathrm{mg}$ did not reduce testosterone concentrations in captive male Trachemys scripta over the course of the study. The higher testosterone concentration observed in the treatment group at $\mathrm{T} 1$ is indicative of the initial stimulatory effect of deslorelin (Fig. 1). The number of studies on gonadal hormones in freshwater turtles (Callard et al., 1976; Licht et al., 1985; McPherson et al., 1982; Shelby et al., 2000) is limited.

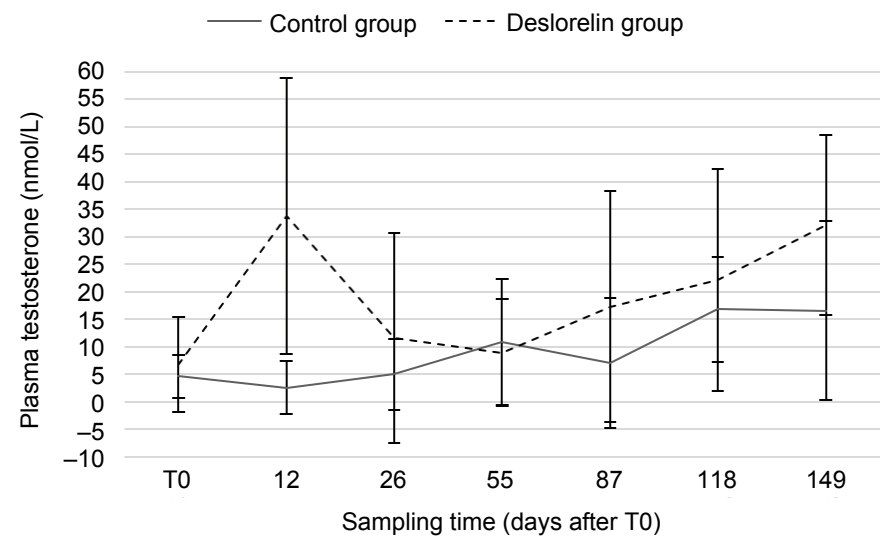

Fig. 1. Mean \pm standard deviation values for plasma testosterone in adult males of Trachemys scripta in the control and treatment group

The present study demonstrates a clear effect of a synthetic GnRH agonist in a chelonian species. A green sea turtle (Chelonia mydas) was implanted each year with a $4.7-\mathrm{mg}$ deslorelin implant for four years and failed to show a seasonal testosterone peak in the fifth year (Graham et al., 2016). Based on this single case, speculation has been made on a possible latent or additive effect of deslorelin to reduce circulating testosterone levels in turtles. In green iguanas no significant difference in testosteronaemia was found between males treated with leuprolide acetate, another GnRH agonist, and a control group (Kirchgessner et al., 2009). Our findings show a stimulatory effect of deslorelin acetate $12 \pm 5$ days after implantation without a negative feedback on pituitary GnRH receptors over the course of the study. This pattern suggests that the dose of $4.7 \mathrm{mg}$ used in our study is too low to elicit a negative feedback and achieve contraceptive effect in Trachemys scripta. Considering that deslorelin acetate does have an effect on the anterior pituitary in Trachemys scripta, it seems fair to assume that a contraceptive effect could be achieved with higher dosage. In domestic turkeys (Meleagris gallopavo) a deslorelin acetate implant has been effective in reducing aggression between two adult males and in decreasing plasma testosterone concentrations (Molter et al., 2015). Knowledge of reptile reproductive physiology is scarce 
compared to mammalian or avian species. However, there is strong evidence to confirm the presence of FSH-like and LH-like gonadotropins in turtles as well as the correlation between FSH-like gonadotropins and testosterone (Callard et al., 1976; Licht et al., 1985). The discrepancy between the lack of effect in reptiles described in this and previous studies compared to the effects recorded in avian and mammalian species treated with long-acting deslorelin implants may be due to the unknown elution and release rate of deslorelin acetate from the implant and the pharmacokinetics of slow-release implants in reptiles. Although limited, the sample size of our study is comparable to a previous study on the seasonal variation in reproductive steroids in freshwater turtles (Shelby et al., 2000). It is hypothesised that male yellow-bellied sliders should exhibit a pattern of seasonal testosterone fluctuation as demonstrated in other freshwater turtle and tortoise species involving a dual peak of testosterone: one peak shortly after the hibernating period and another one in fall (Callard et al., 1976; Licht et al., 1985; Shelby et al., 2000; Currylow et al., 2013). Since T0 took place between 1 April and 5 May, the first peak occurred probably before the beginning of the study. In addition, the length of the study did not cover the second testosterone peak observed in the autumn and therefore it is impossible to conclude on a possible delayed effect of 4.7-mg deslorelin acetate implants. Stress, temperature, daylight and nutrition seem to play an important role in regulating the sexual cycle of male reptiles (Schramm et al., 1999). All males included in our study were kept under the same environmental, housing and feeding conditions. However, the density of male turtles in the pond was elevated compared to their previous housing condition and this parameter could have been a source of competition and chronic stress potentially capable of affecting our results. In conclusion, deslorelin acetate implant at the dose of $4.7 \mathrm{mg}$ has a stimulatory effect on the anterior pituitary in yellow-bellied sliders, and further studies are warranted to determine the effective dose to achieve a negative feedback effect.

\section{Acknowledgements}

Virbac France donated the deslorelin implants. Planete Sauvage, Zoo de Pont Scorff, NaturZoo de Mervent participated in the study. The authors thank Dr. Sandrine Freret and Astrid Monge for their technical assistance.

\section{References}

Callard, I. P., Callard, G. V., Lance, V. and Eccles, S. (1976): Seasonal changes in testicular structure and function and the effects of gonadotropins in the freshwater turtle, Chrysemis picta. Gen. Comp. Endocrinol. 30, 347-356. 
Currylow, A. F., Tift, M. S., Meyer, J. L., Crocker, D. E. and Williams, R. N. (2013): Seasonal variation in plasma vitellogenin and sex steroids in male and female and Eastern Box turtles, Terrapene carolina carolina. Gen. Comp. Endocrinol. 180, 48-55.

Graham, K. M., Mylniczenko, N. D., Burns, C. M., Bettinger, T. L. and Wheaton, C. J. (2016): Examining factors that may influence accurate measurement of testosterone in sea turtles. J. Vet. Diagn. Inv. 28, 12-19.

Kirchgessner, M., Mitchell, M., Domenzain, L., Walden, M., Dickens, M. J. and Romero, B. S. L. M. (2009): Evaluating the effect of leuprolide acetate on testosterone levels in captive male green iguanas (Iguana iguana). J. Herp. Med. Surg. 19, 128-131.

Licht, P., Breitenbach, G. L. and Congdon, J. D. (1985): Seasonal cycles in testicular activity, gonadotropin and thyroxine in the painted turtles, Chrysemis picta, under natural conditions. Gen. Comp. Endocrinol. 59, 130-139.

McPherson, R. J., Boots, L. R., McGregor, RIII. and Marion, K. R. (1982): Plasma steroids associated with seasonal reproductive changes in a multiclutched freshwater turtle, Sternotherus odoratus. Gen. Comp. Endocrinol. 48, 440-451.

Molter, C. M., Fontenot, D. K. and Terrell, S. P. (2015): Use of deslorelin acetate implants to mitigate aggression in two adult male domestic turkeys (Meleagris gallopavo) and correlating plasma testosterone concentrations. J. Avian Med. Surg. 29, 224-230.

Petritz, O. A., Guzman, D. S., Hawkins, M. G., Kass, P. H., Conley, A. J. and Paul-Murphy, J. (2015): Comparison of two 4.7-milligram to one 9.4-milligram deslorelin acetate implants on egg production and plasma progesterone concentrations in Japanese quail (Coturnix coturnix japonica). J. Zoo Wildl. Med. 46, 789-797.

Polo-Cavia, N., López, P. and Martín, J. (2012): Feeding status and basking requirements of freshwater turtles in an invasion context. Physiol. Behav. 105, 1208-1213.

Rowland, M. N. (2011): Use of a deslorelin implant to control aggression in a male bearded dragon (Pogona vitticeps). Vet. Rec. 169, 127.

Schramm, B. G., Casares, M. and Lance, V. A. (1999): Steroid levels and reproductive cycle of the Galápagos tortoise, Geochelone nigra, living under seminatural conditions on Santa Cruz Island (Galápagos). Gen. Comp. Endocrinol. 114, 108-120.

Shelby, J. A., Mendonça, M. T., Horne, B. D. and Seigel, R. A. (2000): Seasonal variation in reproductive steroids of male and female yellow-blotched map turtles, Graptemys flavimaculata. Gen. Comp. Endocrinol. 119, 43-51. 